\title{
Expression pattern of the $p s b O$ gene and its involvement in acclimation of the photosynthetic apparatus during abiotic stresses in Festuca arundinacea and $F$. pratensis
}

\author{
Izabela Pawłowicz • Arkadiusz Kosmala • \\ Marcin Rapacz
}

Received: 4 January 2012/Revised: 27 February 2012/ Accepted: 28 March 2012/Published online: 21 April 2012

(C) The Author(s) 2012. This article is published with open access at Springerlink.com

\begin{abstract}
PsbO, the manganese-stabilizing protein, plays a crucial role in oxygen-evolving complex functioning and stabilization, by maintaining optimal manganese, calcium and chloride concentrations at the active state of PSII. In this paper we present a study focused on recognizing the relationship between $p s b O$ gene activity and acclimation of the photosynthetic apparatus under abiotic stresses in the grasses Festuca arundinacea and $F$. pratensis. PsbO expression was compared between two distinct genotypes within each species which differed in their levels of stress tolerance (drought and frost, respectively) during drought treatment ( $F$. arundinacea) and cold acclimation ( $F$. pratensis). The research involved: (1) the analyses of $p s b O$ gene expression profiles using real-time PCR, and (2) the analyses of PsbO protein accumulation profiles using protein gel blot hybridization. The results indicate that PsbO plays a protective function with respect to the photosynthetic apparatus during abiotic stresses. In cold-treated $F$. pratensis plants the accumulation of PsbO seems to be responsible for differences in the PSII photochemical efficiency. Higher stability of PSII during drought, observed in the high-drought tolerant $F$. arundinacea
\end{abstract}

Communicated by Y. Wang.

I. Pawłowicz $(\varangle) \cdot$ A. Kosmala

Institute of Plant Genetics, Polish Academy of Sciences,

Strzeszyńska 34, 60-479 Poznan, Poland

e-mail: ipaw@igr.poznan.pl

M. Rapacz

Department of Plant Physiology, University of Agriculture in

Kraków, Podłużna 3, 30-239 Cracow, Poland genotype, is not associated with PsbO accumulation, although the degradation of this protein affects destabilization of the oxygen-evolving complex in drought.

Keywords Abiotic stresses - Expression profiles · Festuca $\cdot$ Photoinhibition · Photosystem II · PsbO

\begin{tabular}{|c|c|}
\hline \\
\hline \multicolumn{2}{|c|}{$\begin{array}{l}\text { Abbreviations } \\
\text { CA } \quad \text { Cold acclimation }\end{array}$} \\
\hline$C_{\mathrm{T}}$ & Cycle threshold \\
\hline$\Delta \Delta C_{\mathrm{T}}$ & Delta delta $C_{\mathrm{T}}$ \\
\hline $\mathrm{DI}_{0} / \mathrm{CS}$ & $\begin{array}{l}\text { Amount of energy dissipated in PSII } \\
\text { reaction centers per cross section of the } \\
\text { leaf }\end{array}$ \\
\hline DSI & Drought susceptibility index \\
\hline$F a$ & Festuca arundinacea \\
\hline$F p$ & Festuca pratensis \\
\hline$F_{\mathrm{v}} / F_{\mathrm{m}}$ & $\begin{array}{l}\text { Maximum quantum yield of PSII or the } \\
\text { yield of the energy trapping in PSII }\end{array}$ \\
\hline HDT & High-drought tolerant \\
\hline HFT & High-frost tolerant \\
\hline LDT & Low-drought tolerant \\
\hline LFT & Low-frost tolerant \\
\hline $\mathrm{Lt}$ & Relative electrolyte leakage \\
\hline MSP & Manganese-stabilizing protein \\
\hline OEC & Oxygen-evolving complex \\
\hline Fraction OEC & $\begin{array}{l}\text { The fraction of } \mathrm{O}_{2} \text {-evolving centers in } \\
\text { comparison with the control sample } \\
\text { (chlorophyll fluorescence parameter) }\end{array}$ \\
\hline$Q_{\mathrm{A}}$ & $\begin{array}{l}\text { The first stable electron acceptor in PSII } \\
\text { complex }\end{array}$ \\
\hline$Q_{\mathrm{B}}$ & $\begin{array}{l}\text { The second stable electron acceptor in } \\
\text { PSII complex }\end{array}$ \\
\hline RWC & Relative Water Content \\
\hline SD & Standard deviation \\
\hline
\end{tabular}


SE $\quad$ Standard error

$\%$ Vol Relative volume

\section{Introduction}

Abiotic stresses, such as drought and frost, are the main factors that affect plant production worldwide. Many species have a strong capacity to adapt to these stresses through the activation of different regulatory pathways responsible for stress perception, signal transduction and expression of stress-related genes. Photosynthesis is a metabolic process which is injured in the early stages of the occurrence of stress-induced factors. Photosystem II (PSII), where the oxygen evolution takes place, is highly sensitive to environmental changes, and stress conditions can rapidly reduce its activity (Takahashi and Murata 2008; Yamamoto et al. 2008) and accelerate photodamage in a range of plant species (Flexas et al. 2004; Murata et al. 2007; Pinheiro and Chaves 2011). In all oxygenic photosynthetic organisms PSII is a multi-subunit protein complex located in the thylakoid membrane. The oxygen-evolving complex (OEC) is located at the lumenal side of PSII, and is responsible for water oxidation. In higher plants, the OEC consists of an $\mathrm{Mn}_{4} \mathrm{Ca}$ cluster which binds with several intrinsic and extrinsic proteins. The three main extrinsic proteins: PsbO, PsbP and PsbQ, with apparent molecular masses of 33, 24 and $17 \mathrm{kDa}$, respectively, are required for high rates of oxygen evolution (Bricker and Burnap 2005; Roose et al. 2011). PsbO, called the manganese-stabilizing protein (MSP), was first found in spinach chloroplasts (Kuwabara and Murata 1979) and is highly conserved in higher plants (Bricker and Burnap 2005). It is a nucleus-encoded protein whose precursor is synthesized in the cytoplasm and then transported to the chloroplasts, and finally localized at the lumenal side of PSII (Hashimoto et al. 1997). It is suggested that PsbO is a thermostable protein that exists naturally in an unfolded state (Lydakis-Simantiris et al. 1999). Typically, about $50 \%$ of the total PsbO is present in the soluble pool in the thylakoid lumen (Hashimoto et al. 1996), and these free proteins probably function in maintaining the homeostasis of PSII. PsbO is proposed to play a crucial role in OEC functioning, by maintaining optimal manganese, calcium and chloride concentrations in the active state of PSII (Bricker and Frankel 2011). Moreover, PsbO may participate in the protection of PSII against photodamage, since recent reports indicate that PSII photoinhibition could be initiated exactly at the Mn-cluster stabilized by PsbO (Sarvikas et al. 2006).
The Lolium-Festuca complex of forage grasses contains a number of species with agronomically desirable and complementary traits. Lolium species are high yielding and have excellent forage quality, while Festuca species express stronger persistency and higher tolerance to abiotic and biotic stresses (Thomas and Humphreys 1991). In the present paper we analyzed some aspects of drought and low-temperature tolerance in two Festuca species connected with stability of the photosynthetic apparatus. We found that the differences in drought tolerance between $F$. arundinacea (tall fescue, $2 n=6 x=42, F a$ ) genotypes, as well as differences in frost tolerance between $F$. pratensis (meadow fescue, $2 n=2 x=14, F p$ ) genotypes, are related to $p s b O$ expression profiles observed at low temperature and under drought, respectively. Thus, we expected that changes in $p s b O$ expression level could be connected with the OEC complex stabilization under stress. Genetically based differences in the performance of the photosynthetic apparatus were reported to be closely connected with the whole plant stress tolerance (frost and drought) (Rapacz et al. 2004; Humphreys et al. 2007; Oukarroum et al. 2007). Within the genus Festuca, $F$. pratensis is the most suitable model plant for research into the mechanisms of cold acclimation (CA) and frost tolerance in forage grasses (Kosmala et al. 2006, 2009; Rudi et al. 2011), whereas $F$. arundinacea is a model plant with reference to drought tolerance (Humphreys et al. 2005; Cao et al. 2009). The studies performed on two genotypes for each species, with distinct levels of stress tolerance (frost and drought, respectively) included: (1) the analysis of the $p s b O$ gene expression profiles using realtime PCR and (2), the analysis of PsbO protein accumulation profiles using protein gel blot hybridization.

\section{Materials and methods}

\section{Plant material}

Drought tolerance of $\mathrm{Fa}$ plants was determined on the basis of DSIs (drought susceptibility indexes, Rapacz et al. 2010), calculated for some parameters of chlorophyll ' $a$ ' fluorescence, transiently measured before and during drought treatment in a population of $F$. arundinacea cv. Kord (Pawłowicz and Rapacz 2010). Within a collection of 60 plants the $\mathrm{Fa} 31$ genotype was selected as a high-drought tolerant (HDT) genotype, and Fa35 as a low-drought tolerant (LDT). Frost tolerance of $F p$ plants was estimated based on the ability of plants to regrow after freezing, and on the $T_{\text {EL50 }}$ values (temperature causing a leakage of 50\% leaf electrolytes) after 21 days of cold acclimation in a population of $F$. pratensis cv. Skra (Kosmala et al. 2006, 2007, 2009). Among a population of 40 plants two 
genotypes with extreme values of stress tolerance were used in the current studies: $F p 37\left(T_{\mathrm{EL} 50}=-21.4{ }^{\circ} \mathrm{C}\right)$ as a high-frost tolerant (HFT) plant, and $F p 13 \quad\left(\mathrm{~T}_{\mathrm{EL} 50}=\right.$ $-15.9{ }^{\circ} \mathrm{C}$ ) as a low-frost tolerant one (LFT).

Before stress treatments $F a$ and $F p$ genotypes were acclimated in a sand:peat (1:1) mixture over 14 days in a growth chamber at temperatures of $25 / 17^{\circ} \mathrm{C}$ (day/night), a $16 / 8 \mathrm{~h}$ photoperiod, photosynthetic active radiation (PAR) of $350 \mu \mathrm{mol} \mathrm{m} \mathrm{m}^{-2} \mathrm{~s}^{-1}$ and $60 \%$ relative air humidity.

Drought treatment and plant sample collection

For the application of stress conditions the HDT and LDT genotypes of the $F a$ plants were cut down to a height of $25 \mathrm{~cm}$, with air humidity in the growth chamber reduced to $30 \%$ and watering stopped. The leaves of the seedlings were harvested before stress treatment (control), and after 3, 6 and 8 days of drought and 14 days after rehydration. Relative water content (RWC) (before and after 3, 6 and 8 days of drought treatment and 14 days after rehydration), relative electrolyte leakage (Lt) (before and after 3, 6 and 8 days of drought treatment and 14 days after rehydration) and chlorophyll fluorescence (before and after 8 days of drought treatment) were analyzed for each selected genotype.

\section{Cold treatment and plant sample collection}

Pre-hardening of HFT and LFT $F p$ genotypes was performed during 7 days at $12^{\circ} \mathrm{C}, 8 \mathrm{~h} / 16 \mathrm{~h}$ photoperiod, and PAR of $200 \mu \mathrm{mol} \mathrm{m} \mathrm{m}^{-2} \mathrm{~s}^{-1}$. The plants were then cold acclimated for 21 days $\left(4 / 2{ }^{\circ} \mathrm{C}, 10 / 14 \mathrm{~h}\right.$ photoperiod, and PAR of $200 \mu \mathrm{mol} \mathrm{m} \mathrm{m}^{-2} \mathrm{~s}^{-1}$ ). The youngest but fully expanded and undamaged leaves of the seedlings were harvested before cold acclimation (control) and after 2, 7, 14 and 21 days of cold treatment. Chlorophyll fluorescence analysis was performed before (control) and after 4, 7, 12 and 18 days of cold treatment.

\section{Relative electrolyte leakage (Lt) measurements}

Leaf segments (six replicates of $1 \mathrm{~cm}$ in length) were placed in glass tubes (Sigma) containing $10 \mathrm{~mL}$ of distilled (Milli Q) water, and incubated overnight at room temperature with gentle shaking. Electrical conductivity $\left(L_{1}\right)$ was measured using a conductivity meter (Hanna Instruments EC215 Conductivity Meter). The tubes were then autoclaved, shaken for $1 \mathrm{~h}$ and the electrical conductivity was again measured $\left(L_{2}\right)$. Relative electrolyte leakage was calculated as: $L_{1} / L_{2} \times 100 \%$.

\section{RWC measurements}

The relative water content of leaves was measured to monitor the leaf hydration status. It was calculated as follows: $\mathrm{RWC} \%=(\mathrm{FW}-\mathrm{DW}) /(\mathrm{SW}-\mathrm{DW}) \times 100$, where FW is the leaf fresh weight, DW is the leaf dry weight, and SW is the leaf turgid weight. To obtain DW the collected leaves (leaf fragments) were dried at $85{ }^{\circ} \mathrm{C}$ for 3 days, and to obtain SW leaves were soaked in water for $4 \mathrm{~h}$ at room temperature.

\section{Chlorophyll fluorescence measurements}

Polyphasic chlorophyll ' $a$ ' fluorescence transients (Strasser et al. 1995) was measured in intact leaves by means of a Handy PEA fluorometer (Hansatech), with a light pulse intensity of 3,000 $\mu \mathrm{mol} \mathrm{m} \mathrm{m}^{-2} \mathrm{~s}^{-1}$, pulse duration of $1 \mathrm{~s}$ and fixed gain $(1 \times)$, as previously described (Rapacz 2007). Prior to the measurements leaves were dark adapted for $20 \mathrm{~min}$ in leaf clips (Hansatech, Kings Lynn, UK). Both dark adaptation and measurements were performed at $21 \pm 1{ }^{\circ} \mathrm{C}$. Measurements were taken in 10 replicates (leaves). Among many useful chlorophyll fluorescence parameters measured and calculated using JIP-test (Strasser et al. 2000), three of them are presented in the paper. The decrease in the first of them is $F_{\mathrm{v}} / F_{\mathrm{m}}\left(\varphi P_{0}\right.$, the yield of the energy trapping in PSII, where $F_{\mathrm{m}}$ is maximal fluorescence intensity after saturated light exposition of dark adapted leaves, $F_{0}$ is minimum, or initial, fluorescence under the same conditions and $F_{\mathrm{v}}=F_{\mathrm{m}}-\mathrm{F}_{0}$ ) is commonly considered as a measure of photoinhibition (Powles 1984). The second, $\mathrm{DI}_{0} / \mathrm{CS}$, calculated as: $F_{0}-F_{\mathrm{v}} F_{0} / F_{\mathrm{m}}$ reflects the amount of energy dissipated in PSII reaction centers per leaf cross section (Strasser et al. 2000). This parameter was the most useful for showing the variation in drought tolerance among $F a$ genotypes, as described earlier by Pawłowicz and Rapacz (2010). Estimation for the $\mathrm{O}_{2}$-evolving centers (OEC) was reported to be calculated by utilizing the JIP-test (Appenroth et al. 2001). The K step of chlorophyll fluorescence induction kinetics in the dark adapted sample, at about $300 \mu \mathrm{s}$, is due to deactivation of oxygen-evolving centers. Applying this useful information it is possible to calculate the fraction of $\mathrm{O}_{2}$-evolving centers in comparison with the control sample as: fraction $\mathrm{OEC}=\mathrm{OEC}$ treated/OEC control, where OEC $=1-V_{\mathrm{k}} /$ $V_{\mathrm{j}}$, where $V_{\mathrm{k}}=\left(F_{0.3 \mathrm{~ms}}-\mathrm{F}_{0.05 \mathrm{~ms}}\right) /\left(F_{\mathrm{m}}-F_{0.05 \mathrm{~ms}}\right)$ and $V_{\mathrm{j}}=\left(\mathrm{F}_{2 \mathrm{~ms}}-F_{0}\right) /\left(F_{\mathrm{m}}-F_{0}\right) . F_{0.05 \mathrm{~ms}}, F_{0.3 \mathrm{~ms}}$ and $F_{2 \mathrm{~ms}}$ are fluorescence intensities recorded after $0.05,0.3$ and $2 \mathrm{~ms}$ of saturated light exposition of dark adapted leaves, respectively. 
RNA isolation and quantitative real-time PCR (qRT-PCR) analyses

Total RNA was isolated using Tri-reagent (Novazym), followed by DNase I treatment to remove any genomic DNA contaminants. RNA concentration was determined with a spectrophotometer (NanoDrop ND-1000, NanoDrop Technologies INC). $1 \mu \mathrm{g}$ of total RNA was reverse transcribed to obtain the first-strand cDNA, using Transcriptor First Strand cDNA Synthesis Kit (Roche), and according to the manufacturer's instruction. Quantitative RT-PCR was carried out using the BioRad CFX96 Real-Time PCR Detection System. Each reaction contained $12.5 \mu \mathrm{l}$ of $2 \times$ SYBR Master Mix reagent (Roche), $1.5 \mu \mathrm{l}$ of $1: 4$ diluted cDNA, and $150 \mathrm{nM}$ of each gene-specific primer in a final volume of $25 \mu \mathrm{l}$. PCR cycling was: $95^{\circ} \mathrm{C}$ for $10 \mathrm{~min}$, followed by 46 cycles of $95{ }^{\circ} \mathrm{C}$ for $15 \mathrm{~s}, 55^{\circ} \mathrm{C}$ for $1 \mathrm{~min}$ and $72^{\circ} \mathrm{C}$ for $40 \mathrm{~s}$. Fluorescence reading was performed during the annealing phase of each cycle. The specificity of the reactions was verified by melting curve analysis (from 55 to $95{ }^{\circ} \mathrm{C}$ with fluorescence intensity reading every $0.5 \mathrm{~s}$ and maximum ramp rate $5^{\circ} \mathrm{C} / \mathrm{s}$ ). Primers were designed using the Roche Universal Library Application, targeting an amplicon size of 60 base pairs for psbO and 65 base pairs for $\beta$-actin. Primer sequences are listed in Table 1 . The relative mRNA level for the target gene was calculated as $\Delta \Delta C_{\mathrm{T}}$ values. In order to compare data from different cDNA samples (collected in different time points of cold acclimation and drought stress), $C_{\mathrm{T}}$ values for the analyzed genes were normalized to the $C_{\mathrm{T}}$ value of $\beta$-actin gene from $F$. pratensis. All real-time PCR reactions were repeated three times, each time using a different clone of the selected genotype (three biological replicates). Statistical significance of the differences in the parameters studied were tested using Tuckey's HSD test at $P=0.05$ after two-way ANOVA analysis, where stress and genotype were the factors (Statistica 9.0, Statsoft, Tulsa, OK, USA). Relative values were compared using non-parametrical Mann-Whitney's $U$ test.

Total protein extraction and protein gel blot hybridization

$50 \mathrm{mg}$ of leaf fresh weight were ground in liquid nitrogen and homogenized in extraction buffer containing $50 \mathrm{mM}$ Tris-
$\mathrm{Cl}, \mathrm{pH}$ 8.0, $1 \%$ SDS and $0.1 \% \beta$-mercaptoethanol. The homogenate was centrifuged at $14,000 \times g$ for 15 min at $0{ }^{\circ} \mathrm{C}$. Proteins were precipitated by adding four volumes of precooled acetone to the supernatants with incubation at $-20{ }^{\circ} \mathrm{C}$ overnight. Proteins were then collected through centrifugation at $14,000 \times g$ for $15 \mathrm{~min}$ at $0{ }^{\circ} \mathrm{C}$. The pellet was washed twice with ice-cold $80 \%(\mathrm{v} / \mathrm{v})$ acetone, dried at room temperature and resuspended in the buffer $(3 \%$ SDS, $4 \%$ $\beta$-mercaptoethanol, 125 mM Tris- $\mathrm{Cl}, \mathrm{pH} 6.7,10 \%$ glycerol, bromophenol blue) by vortexing and incubating for $1 \mathrm{~h}$ at room temperature. The protein concentration in the extracts was determined using the 2D-Quant Kit (GE Healthcare). $15 \mu \mathrm{g}$ of proteins were separated in $13 \%$ SDS-polyacrylamide gel (SDS-PAGE), and electroblotted into nitrocellulose membranes (Perkin Elmer). Immunodetection was performed with rabbit polyclonal anti-PsbO $(1: 10,000)$ antibody (Agrisera). The antigen-antibody complexes were detected by a chemiluminescent detection system with alkaline phosphatase-linked anti-rabbit IgG (Sigma). Following protein gel blot hybridisation the membranes were scanned by ImageScanner III (GE Healthcare) and subjected to LabScan 6.0 program (GE Healthcare) processing. Band detection and image analyses (normalization, protein accumulation analyses, statistics) were performed with Image Master 2-D Platinum software (GE Healthcare). The abundance of each protein band was normalized as a relative volume (\% Vol). The \% Vol of each band was automatically calculated by Image Master software as a ratio of the volume of particular band to the total volume of all the bands present on the membrane. The extraction procedure and electrophoretic separation were performed three times, each time using a different clone of the selected genotype, and the \% Vol for the bands from the three replicated membranes were then used to calculate means and standard deviations, which were used to create the detailed protein accumulation profiles for each of the selected genotypes.

\section{Results}

The effects of drought treatment and subsequent rehydration on $F$. arundinacea genotypes

The initial (control) level of RWC did not differ between HDT and LDT genotypes (Fig. 1A). Under stress

Table 1 Sequences of primers used for qRT-PCR

\begin{tabular}{llll}
\hline Gene description and origin & Forward primer & Reverse primer & Length of amplicon (bp) \\
\hline psbO (T. aestivum, X57408) & TGTGTGCATGCGTACGTG & CACACATTGTTGCCTCGATT & 60 \\
$\beta$-Actin $($ F . pratensis $)$ & GCGTGTGGAAGACATAACC & TTGGATTCTGGAGATGGTGTC & 65 \\
\hline
\end{tabular}




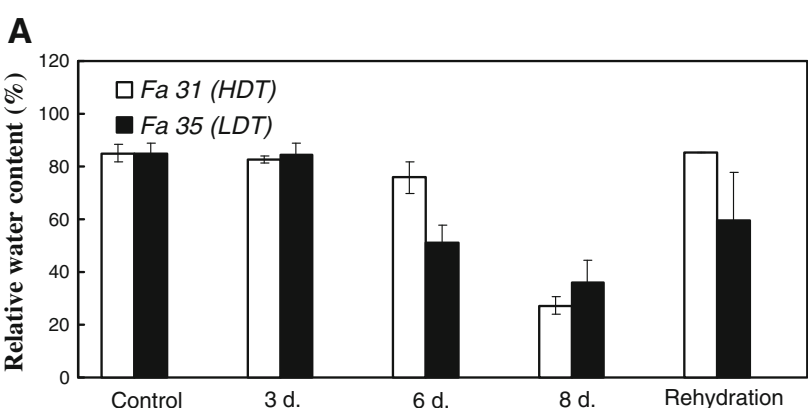

B

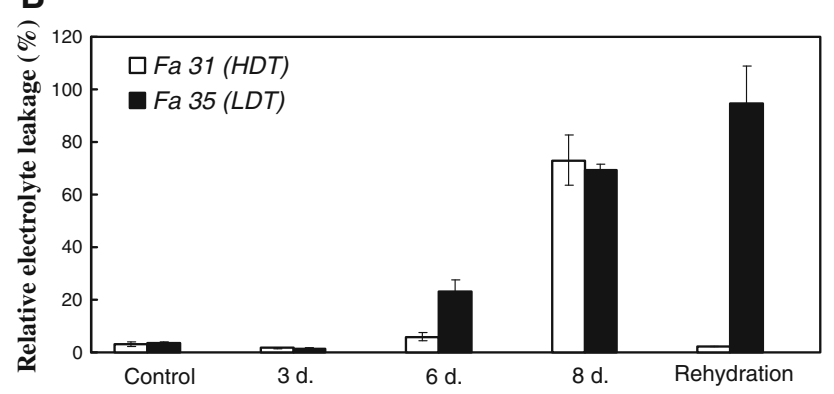

Fig. 1 Relative water content (RWC, \%) (A) and relative electrolyte leakage (Lt, \%) (B) of Fa31 (HDT) and Fa35 (LDT) genotypes under drought stress. Fully expanded leaves were collected from wellwatered control plants, plants exposed to 3, 6 and 8 days of water deficit and rehydrated plants. The data represents means of three replicates and $\mathrm{SD}(P \leq 0.05)$

conditions faster water loss was observed in the LDT genotype, where the highest decrease of this parameter was observed between the third and the sixth day of the drought. After rehydration RWC increased to the level observed before drought treatment in the HDT plant only, whereas it remained slightly lower in the LDT plant.

Lt values increased until the eighth day of stress in both genotypes (Fig. 1B). During rehydration electrolyte leakage recovery to the initial level was observed in the HDT plant only, though a further increase was observed in the LDT plant. The results suggest that the high-drought tolerant species is drought tolerant because it has the capacity to recover quickly from the damage imposed by the stress.

No statistically significant difference in $F_{\mathrm{v}} / F_{\mathrm{m}}$ was observed between control (well-watered) plants of both genotypes studied, but the value of this parameter was significantly lower in the LDT plant after drought (Fig. 2A). This suggests that under conditions of water deficit PSII reaction centers are better protected against photoinhibition in drought tolerant, than in drought susceptible plants. Additionally, in drought-treated plants the lower energy dissipation from PSII reaction centers $\left(\mathrm{DI}_{0} /\right.$ CS) was observed in the HDT genotype (Fig. 2B). Drought also affected the activity of OEC measured by means of chlorophyll fluorescence parameter fraction OEC (Fig. 2C). The parameter decreased in both genotypes
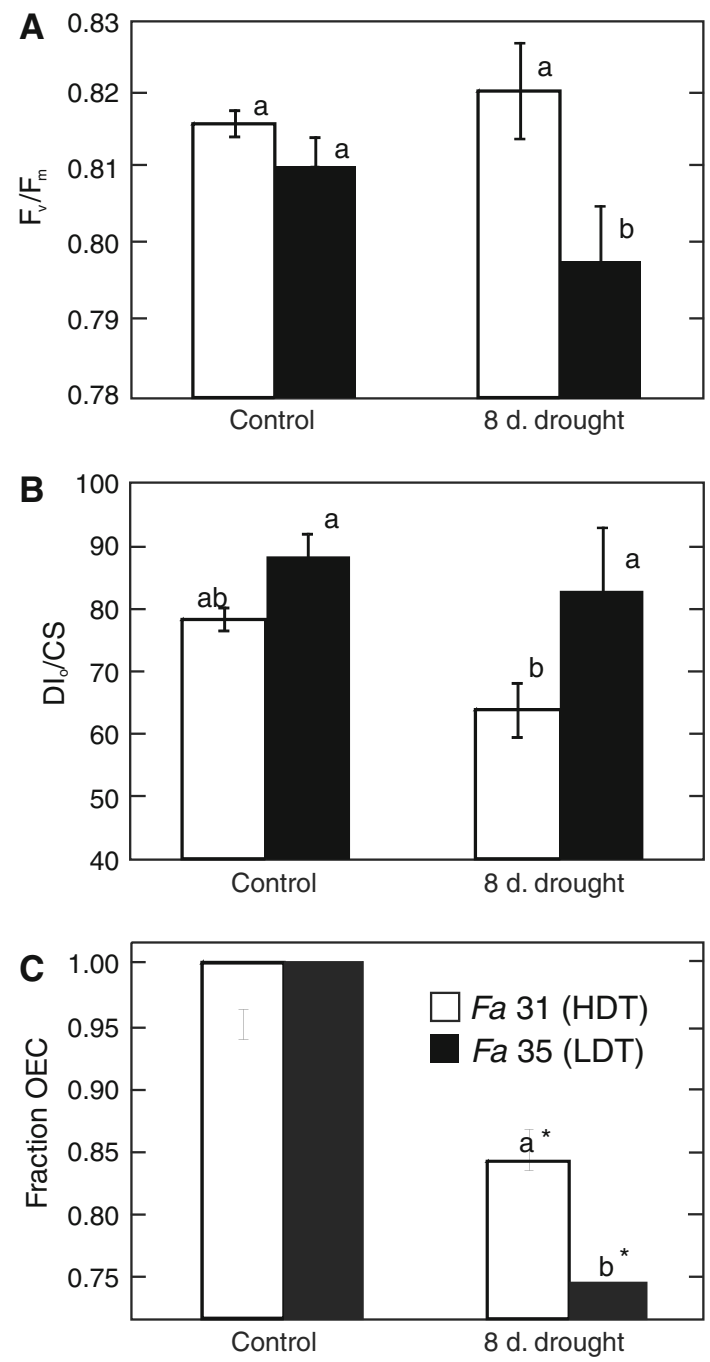

Fig. 2 Changes in quantum yield of energy trapping in PSII reaction centers $\left(F_{\mathrm{v}} / F_{\mathrm{m}}\right)(\mathbf{A})$; energy dissipation from PSII reaction centers $\left(\mathrm{DI}_{0} / \mathrm{CS}\right)(\mathbf{B})$ and the fraction of active $\mathrm{O}_{2}$ evolving centers in comparison with the value at day 0 (fraction OEC) (C) measured by means of chlorophyll fluorescence fast induction kinetics analysis observed between control and drought-treated plants (8 days) of $\mathrm{Fa}$ plants with contrasting drought tolerance: Fa31 (HDT) and Fa35 (LDT). Means of 7-10 replications \pm SE. The values of $F_{\mathrm{v}} / F_{\mathrm{m}}$ and $\mathrm{DI}_{0} / \mathrm{CS}$ denoted with the same letter did not differ statistically, according to Tuckey's HSD test $(P=0.05)$. The values of fraction OEC marked with asterisk are statistically different from the control, and marked with different letters to distinguish genotypes at 8 days under drought, at $P=0.05$ (Mann-Whitney's $U$ test)

during drought, and this decrease was higher in the LDT genotype Fa35.

In the HDT genotype changes of $p s b O$ transcript accumulation were observed during the drought (Fig. 3A). The level of transcripts increased on the third day of the stress, then dropped down on the sixth day, and increased again on day eight. After subsequent rehydration the $p s b O$ transcripts maintained a level similar to that reached in the eighth day of water stress. In the LDT plant transcript 
accumulation increased significantly only on the eighth day of the stress, and dropped again to the control level after rehydration (Fig. 3A).

In both $\mathrm{Fa}$ genotypes under drought conditions a progressive decrease in the abundance of the $\mathrm{PsbO}$ protein was observed (Fig. 3C). Additionally, in the HDT genotype a strong decrease in the accumulation was also noticed between the sixth and the eighth day of stress treatment. A significant difference between the LDT and HDT genotypes in PsbO accumulation level was observed only on the eighth day of drought treatment. After rehydration the accumulation of PsbO in the LDT genotype increased back to the level observed in the HDT genotype.

The fact that the PsbO protein does not accumulate in parallel with accumulation of $p s b O$ transcripts is not surprising. The relationship between the transcriptome and the proteome is complex, and this relationship is often disturbed, mainly by the post-transcriptional steps of gene expression, involving the level of proteolysis (Canovas et al. 2004).

The effects of cold treatment on $F$. pratensis genotypes

During cold treatment a distinct reaction of the photosynthetic apparatus was observed between $F p$ genotypes. Although a decrease in $F_{\mathrm{v}} / F_{\mathrm{m}}$ was observed in both genotypes during the cold period, both initial and final values were similar. The decrease of $F_{\mathrm{v}} / F_{\mathrm{m}}$ was faster in the LFT genotype, and this genotype showed a much lower quantum yield of energy trapping in PSII at the seventh and the 11th day of CA compared to the HFT plant, which suggests its higher susceptibility to lowtemperature-induced photoinhibition (Fig. 4A). In the beginning of cold treatment the HFT genotype was characterized by a higher value of $\mathrm{DI}_{0} / \mathrm{CS}$ (Fig. 4B). In the LFT plant the fastest increase in $\mathrm{DI}_{0} / \mathrm{CS}$ was observed during the first week of cold treatment, and thereafter its values decreased slightly, reaching the level of the HFT plant at the end of the experiment. In the meantime higher amounts of light energy dissipated from PSII reaction centers were always observed in the LFT genotype. The low-temperature treatment had no significant effect on the fraction OEC, indicating the relative stability of OEC function at low temperature in both genotypes (Fig. 4C).

Two-day cold treatment did not significantly affect $p s b O$ transcript accumulation in LFT plants, although a decrease in $p s b O$ transcript level was observed on the following days. On the 21st day of CA the transcript level increased slightly, but not significantly, in the LFT genotype. In HFT plants the expression profile of the analyzed gene was quite different. After 2 days of cold treatment a lower level of $p s b O$ transcript, compared with the control, was observed.

\section{A}

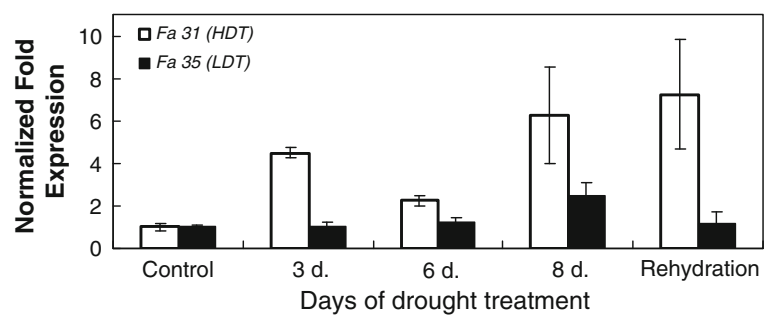

B
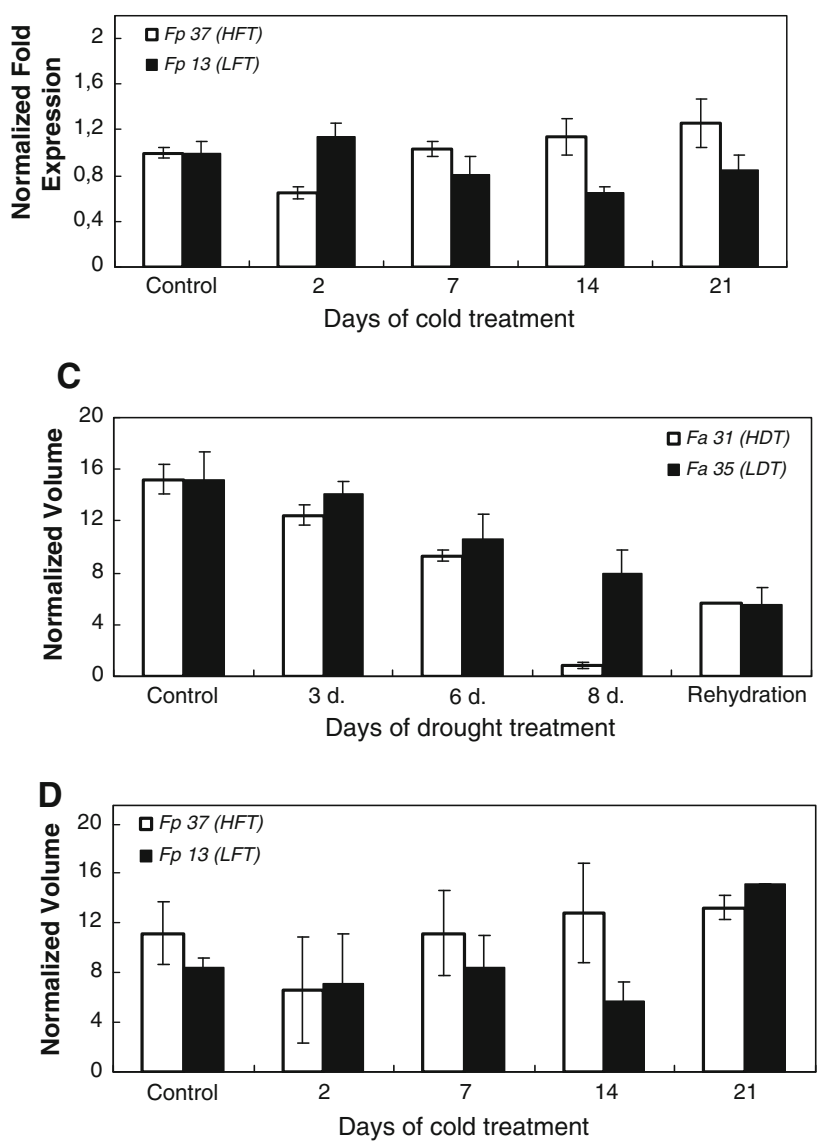

Fig. 3 qRT-PCR analysis of $p s b O$ transcript level in $F a$ plants under drought conditions (A) and $F$ p plants during cold acclimation (B). Fully expanded leaves of $\mathrm{Fa}$ were collected from well-watered control plants, plants exposed to 3,6 and 8 days of drought and rehydrated plants. Leaves of $F p$ were collected before cold acclimation and after 2, 7, 14 and 21 days of cold treatment. The relative mRNA level for the $p s b O$ gene was calculated as $\Delta \Delta C_{\mathrm{T}}$ values. The data represents means of three replicates and $\mathrm{SD}(P \leq 0.05)$. Immunoblot analysis of PsbO accumulation in $F a$ plants under drought conditions $(\mathbf{C})$, and in $F p$ plants during cold acclimation $(\mathbf{D})$. Leaves of $F a$ were collected from well-watered control plants, plants exposed to 3, 6 and 8 days of drought and rehydrated plants; leaves of $F p$ were collected before cold acclimation and after 2, 7, 14 and 21 days of cold treatment. $15 \mu \mathrm{g}$ of total protein extracts were separated by $13 \%$ SDS-PAGE, transferred to nitrocellulose membrane and probed with anti-PsbO antibody. \% Vol (relative volume) of each band was automatically calculated by Image Master software as a ratio of the volume of particular band to the total volume of all the bands present on the membrane. The data represents means of three replicates and $\mathrm{SD}(P \leq 0.05)$ 

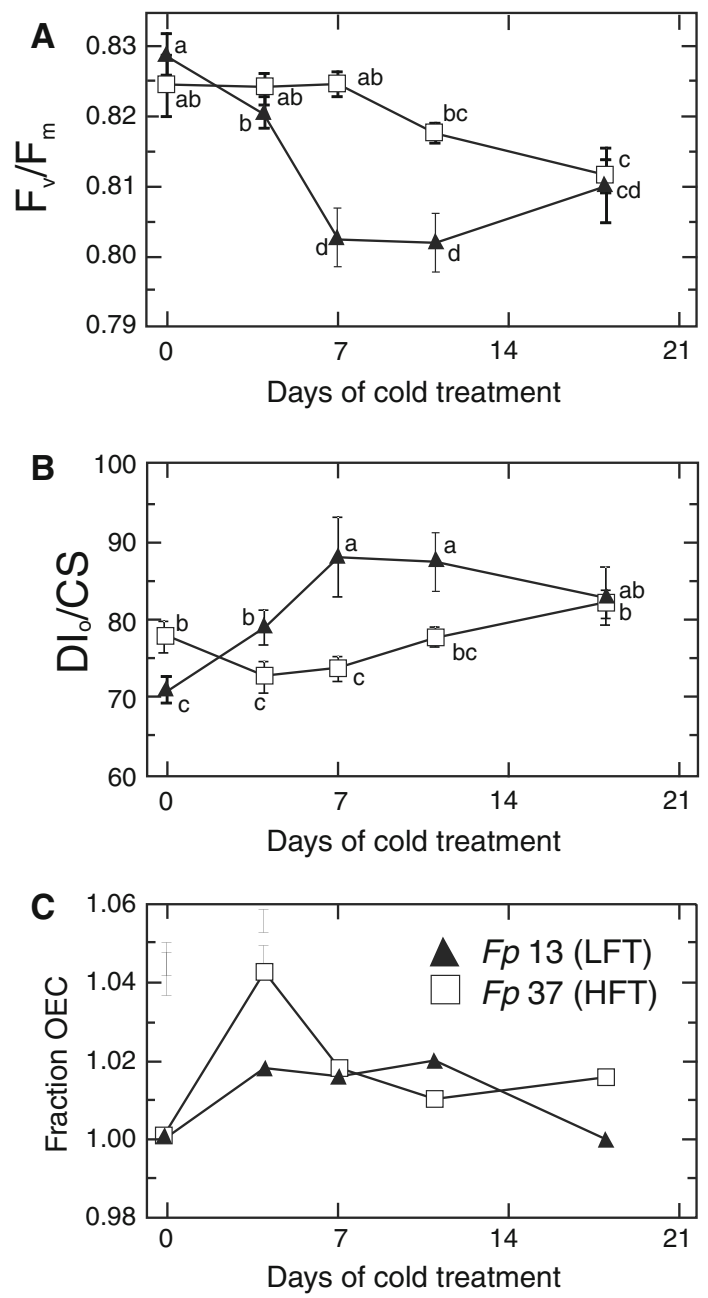

Fig. 4 Changes in quantum yield of energy trapping in PSII reaction centers $\left(F_{\mathrm{v}} / F_{\mathrm{m}}\right)(\mathbf{A})$, energy dissipation from PSII reaction centers $\left(\mathrm{DI}_{0} / \mathrm{CS}\right)(\mathbf{B})$ measured by means of chlorophyll fluorescence fast induction kinetics analysis observed during cold treatment $\left(4 / 2{ }^{\circ} \mathrm{C}\right.$, day/night, photoperiod 10/14 h) of $F p$ plants contrasting in their frost tolerance: $F p 13$ (LFT) and Fp37 (HFT). Means of 7-10 replications \pm SE $(\mathbf{a}, \mathbf{b}), \mathbf{c}-$ relative values. The values of single parameter denoted with the same letter did not differ statistically according to Tuckey's HSD test $(P=0.05)$. In the case of fraction OEC any statistically significant differences from the control were found at $P=0.05$

However, on the following days its level increased and it was significantly higher compared to the initial steps of CA (Fig. 3B).

The accumulation level of the PsbO protein did not differ significantly between HFT and LFT genotypes until the seventh day of cold acclimation, but it was slightly higher before cold treatment (control conditions) for the HFT plant. On the 14th day of cold treatment its level was higher in the HFT genotype (a significant decline was observed in the LFT plant), but on the 21st day of CA it was higher in the LFT genotype (Fig. 3D).

\section{Discussion}

In the present paper the first analysis of $p s b O$ gene expression profiles under drought and cold treatments, with the reference to the plant stress tolerance and photosynthetic apparatus efficiency, is presented. Two model forage grass species, $F$. arundinacea and $F$. pratensis, were used. The aim was to discover if distinct abiotic stresses: drought in $F$. arundinacea and low temperature in $F$. pratensis, may affect $p s b O$ gene expression, and to see if the patterns of these changes are connected with the differences in stress tolerance level observed between distinct genotypes of $\mathrm{Fa}$ and $F p$. The results revealed that both drought and cold treatment caused changes in transcript and protein level of $p s b O$ in $F a$ and $F p$, respectively; but only in $F$. pratensis the higher frost tolerance of $F p 37$ genotype was connected with PsbO accumulation.

A complex proteomic study performed earlier in $F p$ showed that the response to cold treatment on the protein level varies during CA between $F p$ genotypes with contrasting levels of frost tolerance (HFT and LFT) (Kosmala et al. 2009). The study focused on the analyses of leaf protein accumulation before stress treatment, and dynamically during $\mathrm{CA}$, using a high-throughput two-dimensional electrophoresis (2-DE), and on the identification of proteins which were accumulated differentially between the selected plants by the application of mass spectrometry. Among a set of changes observed by Kosmala et al. (2009) it was noticed that PsbO protein was partially degraded during cold treatment, and the products of its degradation were found in numerous protein spots in 2-D maps. To evaluate the total level of PsbO accumulation during $\mathrm{CA}$, and the differences between the HFT and LFT genotypes, the analysis of $p s b O$ gene expression at the transcript (realtime PCR) and the protein level (protein gel blot hybridization) was performed herein. Additionally, the same analysis was carried out on $F a$ genotypes with contrasting levels of drought tolerance (HDT and LDT) during drought stress.

The studies of the $p s b O$ gene expression patterns during CA revealed differences in its expression between HFT and LFT $F p$ plants. Higher accumulation of PsbO in the HFT genotype may indicate that acclimation process of the photosynthetic apparatus took place. Genotypes of $\mathrm{Fa}$ studied in our experiments showed both a distinct reaction of photosynthetic apparatus and different patterns of $p s b O$ transcription and protein accumulation during cold treatment. It has been demonstrated several times that, due to partially overlapping mechanisms of CA to frost conditions and to cold-induced photoinhibition, more frost tolerant plants tend to be also more tolerant to cold-induced photoinhibition of photosynthesis (Sandve et al. 2011). In our work plants were grown for 1 week at $12{ }^{\circ} \mathrm{C}$, a photoperiod 
8/16 and PAR of $200 \mu \mathrm{mol} \mathrm{m} \mathrm{m}^{-2} \mathrm{~s}^{-1}$ before cold acclimation (Kosmala et al. 2009), and during this pre-hardening period the acclimation of photosynthetic apparatus to cold should have occurred (Rapacz 1998). Thus the decrease in $F_{\mathrm{v}} / F_{\mathrm{m}}$ (quantum yield of energy trapping in PSII reaction centers) observed during cold $\left(4 / 2{ }^{\circ} \mathrm{C}\right)$ treatment, together with the increase in $\mathrm{DI}_{0} / \mathrm{CS}$, indicates the decrease in the efficiency of electron transfer after PSII reaction centers reflected further damage, rather than more acclimation of the photosynthetic apparatus. The HFT genotype showed a higher overall performance index of PSII, as well as higher quantum efficiency of electron transfer downstream of PSII reaction centers, as measured by means of chlorophyll fluorescence (Rapacz 2007) during the whole cold treatment (data of these parameters are not shown). This observation is in accordance with the earlier results in which more freezing tolerant genotypes of Lolium-Festuca grasses were characterized with better photosynthetic acclimation to cold (Rapacz et al. 2004; Humphreys et al. 2007). In higher plants two main strategies of acclimation of the photosynthetic apparatus during exposure to low temperatures have evolved: the photochemical mechanism and the non-photochemical mechanism (Sandve et al. 2011). In the present work the higher values of $\mathrm{DI}_{0} / \mathrm{CS}$ observed before low-temperature treatment in the HFT $F p$ genotype confirm the former results of Humphreys et al. (2007), that a non-photochemical mechanism of photosynthetic acclimation was observed in $F$. pratensis. The pattern of changes in chlorophyll fluorescence parameters observed during cold treatment in $F p$ genotypes of different freezing tolerance capacities was similar to the pattern of changes in PsbO protein accumulation. The higher level of protein was observed on the seventh and the 14th day in the HFT compared to LFT plant, in which at these time points lower values of $F_{\mathrm{v}} / F_{\mathrm{m}}$ and higher of $\mathrm{DI}_{0} / \mathrm{CS}$ were observed. Similar levels of PsbO accumulation were observed in both genotypes around the 18th day of cold acclimation, when the trapping efficiencies of PSII reaction centers were also similar. Because cold treatment did not affect the efficiency of oxygen-evolving complex in $F p$, the other protective function of PsbO rather than OEC preservation should be taken into consideration. It is well known that PsbO can participate in calcium binding (Heredia and De Las Rivas 2003; Murray and Barber 2006) and stabilization of PSII dimeric structure. PsbO also reveals carbonic anhydrase activity and plays a molecular chaperone-like role in PSII (Yamamoto et al. 1998; Yamamoto 2001). GTP binding of PsbO during the process of GTP-dependent degradation of the PSII reaction center D1 subunit (Lundin et al. 2007; Spetea et al. 2004) was also observed.

In $F$. arundinacea the downregulation of $\mathrm{PsbO}$ in drought was observed. Drought, such as freezing and salinity, is thought to be among the strongest stresses causing cell dehydration. The present study has revealed that the HDT plant was more drought tolerant compared to the LDT one both in the aspect of water balance, membrane stability and the stability of the photosynthetic apparatus during drought treatment. The efficiency of the oxygen-evolving complex significantly decreased in drought-treated $F a$ plants. A dissociation of the oxygenevolving complex and the decrease in its efficiency was earlier reported as the main effect of drought on photosynthetic light processes (De Ronde et al. 2004; Oukarroum et al. 2007). Oukarroum et al. (2007) also reported that more drought tolerant barley plants were characterized with a lower rate of decrease of oxygenevolving complex efficiency measured by means of chlorophyll fluorescence transient. A similar effect was also observed for $F a$ in our study. On the other hand, these differences in the stabilization of oxygen-evolving complex between $\mathrm{Fa}$ genotypes were not related with the accumulation of $\mathrm{PsbO}$ protein, which was always lower in the HDT genotype. Because the HDT genotype was characterized with a slower rate of water loss it seems to be possible that the distinct accumulation of some osmolytes, such as glycine, betaine or proline may be responsible for the differences in OEC observed between genotypes, as was suggested by Papageorgiou and $\mathrm{Mu}-$ rata (1995) and De Ronde et al. (2004). The same compounds are responsible for many physiological effects, including thylakoid membrane stabilization, which may impinge on the efficiency of the PSII acceptor site (Ashraf and Foolad 2007). In our experiment $\mathrm{DI}_{0} / \mathrm{CS}$, which reflects energy flow imbalance between the acceptor and donor site of PSII, was not affected by drought, and was always lower in the HDT genotype, making it possible that another factor may be involved in the stabilization of the donor site of PSII in $\mathrm{Fa}$ genotypes studied here; and it may even be responsible also for differences in OEC observed before drought. On the other hand, it seems possible that the decrease in OEC observed during drought treatment may be connected with the decreased amount of native PsbO protein during treatment, and that the $p s b O$ transcription was up regulated by the decreased protein level.

In conclusion, the role of $\mathrm{PsbO}$ protein in the protection of photosynthetic apparatus differs in drought and during cold acclimation. In cold-treated $F p$ plants the accumulation of PsbO may, to some extent, explain the differences in the PSII photochemical efficiency. The differences in the stability of PSII during drought, observed between $\mathrm{Fa}$ genotypes of different water deficit tolerance, are not connected with PsbO accumulation, although the degradation of this protein most probably affects destabilization of the oxygen-evolving complex in drought. 
Author contribution I. Pawłowicz and A. Kosmala were responsible for the experimental design. I. Pawłowicz ran the experiments and wrote the paper. A. Kosmala was responsible for analysis of the proteomic data, and was also involved in preparation of the manuscript. M. Rapacz was involved in the physiological work, interpretation of physiological results and also took part in preparation of the manuscript.

Acknowledgments The $F p$ plants were selected in the frame of the project of the Polish Ministry of Science and Higher Education (no. 2 P06A 044 30). We would like to thank Professor Neil Jones from Aberystwyth University UK for critical reading and correction of the manuscript.

Open Access This article is distributed under the terms of the Creative Commons Attribution License which permits any use, distribution, and reproduction in any medium, provided the original author(s) and the source are credited.

\section{References}

Appenroth KJ, Stockel J, Srivastava A, Strasser RJ (2001) Multiple effects of chromate on the photosynthetic apparatus Spirodela polyrhiza as probed by OJIP chlorophyll $a$ fluorescence measurements. Environ Pollut 115:49-64

Ashraf M, Foolad MR (2007) Roles of glycine betaine and proline in improving plant abiotic stress resistance. Env Exp Bot 59:206-216. doi:10.1016/j.envexbot.2005.12.006

Bricker TM, Burnap RL (2005) The extrinsic proteins of photosystem II. In: Wydrzynski T, Satoh K (eds) Photosystem II: the water/ plastoquinone oxido-reductase of photosynthesis. Springer, Dordrecht, pp 95-120

Bricker TM, Frankel LK (2011) Auxiliary functions of the PsbO, PsbP and PsbQ proteins of higher plant Photosystem II: a critical analysis. J Photochem Photobiol B 104:165-178. doi:10.1016/j. jphotobiol.2011.01.025

Canovas FM, Dumas-Gaudot E, Recorbet G, Jorrin J, Mock HP, Rossignol M (2004) Plant proteome analysis. Proteomics 4:285-298. doi:10.1002/pmic.200300602

Cao YJ, Wei Q, Liao Y, Song HL, Li X, Xiang CB, Kuai BK (2009) Ectopic overexpression of AtHDG11 in tall fescue resulted in enhanced tolerance to drought and salt stress. Plant Cell Rep 28:579-588. doi:10.1007/s00299-008-0659-x

De Ronde JA, Cress WA, Krüger GHJ, Strasser RJ, Van Staden J (2004) Photosynthetic response of transgenic soybean plants, containing an Arabidopsis P5CR gene, during heat and drought stress. J Plant Physiol 161:1211-1224. doi:10.1016/j.jplph. 2004.01.014

Flexas J, Bota J, Loreto F, Cornic G, Sharkey TD (2004) Diffusive and metabolic limitations to photosynthesis under drought and salinity in $\mathrm{C}_{3}$ plants. Plant Biol 6:269-279. doi:10.1055/s-2004820867

Hashimoto A, Yamamoto Y, Theg SM (1996) Unassembled subunits of the photosynthetic oxygen-evolving complex present in the thylakoid lumen are long-lived and assembly-competent. FEBS Lett 391:29-34. doi:10.1016/0014-5793(96)00686-2

Hashimoto A, Ettinger WF, Yamamoto Y, Theg SM (1997) Assembly of newly imported oxygen-evolving complex subunits in isolated chloroplasts: site of assembly and mechanism of binding. Plant Cell 9:441-452
Heredia P, De Las Rivas J (2003) Fluorescence induction of Photosystem II membranes shows the step till reduction and protonation of the quinine pool. J Plant Physiol 160:1499-1506. doi:10.1078/0176-1617-01011

Humphreys J, Harper JA, Armstead IP, Humphreys MW (2005) Introgression-mapping of genes for drought resistance transferred from Festuca arundinacea var. glaucescens into Lolium multiflorum. Theor Appl Genet 110:579-587. doi:10.1007/s00122004-1879-2

Humphreys MW, Gąsior D, Leśniewska-Bocianowska A, Zwierzykowski Z, Rapacz M (2007) Androgenesis as a means of dissecting complex genetic and physiological controls: selecting useful gene combinations for breeding freezing tolerant grasses. Euphytica 158:337-345. doi:10.1007/s10681-006-9240-2

Kosmala A, Zwierzykowski Z, Gasior D, Rapacz M, Zwierzykowska E, Humphreys MW (2006) GISH/FISH mapping of genes for freezing tolerance transferred from Festuca pratensis to Lolium multiflorum. Heredity 96:243-251. doi:10.1038/sj.hdy.6800787

Kosmala A, Zwierzykowski Z, Zwierzykowska E, Luczak M, Rapacz M, Gasior D, Humphreys MW (2007) Introgression mapping of genes for winter hardiness and frost tolerance transferred from Festuca arundinacea into Lolium multiflorum. J Hered 98:311-316. doi:10.1093/jhered/esm047

Kosmala A, Bocian A, Rapacz M, Jurczyk B, Zwierzykowski Z (2009) Identification of leaf proteins differentially accumulated during cold acclimation between Festuca pratensis plants with distinct levels of frost tolerance. J Exp Bot 60:3595-3609. doi: 10.1093/jxb/erp205

Kuwabara T, Murata N (1979) Purification and characterization of 33 kilodalton protein of spinach chloroplasts. Biochim Biophys Acta 581:228-236

Lundin B, Thuswaldner S, Shutova T, Eshaghi S, Samuelsson G, Barber J, Andersson B, Spetea C (2007) Subsequent events to GTP binding by the plant PsbO protein: structural changes, GTP hydrolysis and dissociation from the photosystem II complex. Biochim Biophys Acta 1767:500-508. doi:10.1016/j.bbabio. 2006.10.009

Lydakis-Simantiris N, Hutchison RS, Betts SD, Barry BA, Yocum CF (1999) Manganese stabilizing protein of photosystem II is a thermostable, natively unfolded polypeptide. Biochemistry 38:404-414. doi:10.1021/bi981847z

Murata N, Takahashi S, Nishiyama Y, Allakhverdiev SI (2007) Photoinhibition of photosystem II under environmental stress. Biochim Biophys Acta 1767:414-421. doi:10.1016/j.bbabio. 2006.11.019

Murray JW, Barber J (2006) Identification of a calcium-binding site in the PsbO protein of photosystem II. Biochemistry 4:4128-4130. doi:10.1021/bi052503t

Oukarroum A, EL Madidi S, Schansker G, Strasser RJ (2007) Probing the responses of barley cultivars (Hordeum vulgare L.) by chlorophyll $a$ fluorescence OLKJIP under drought stress and rewatering. Environ Exp Bot 60:438-446. doi:10.1016/j. envexpbot.2007.01.002

Papageorgiou GC, Murata N (1995) The unusually strong stabilizing effects of glycinebetaine on the structure and function of the oxygen-evolving photosystem II complex. Photosynth Res 44:243-252

Pawłowicz I, Rapacz M (2010) Genotype differences in drought tolerance of photosynthetic apparatus in $F$. arundinacea Schreb. are connected with the $\mathrm{Cu}-\mathrm{Zn}$ SOD protein accumulation. Zeszyty Problemowe PNR 545:191-197

Pinheiro C, Chaves MM (2011) Photosynthesis and drought: can we make metabolic connections from available data? J Exp Bot 62:869-882. doi:10.1093/jxb/erq340

Powles S (1984) Photoinhibition of photosynthesis induced by visible light. Annu Rev Plant Physiol 35:15-44 
Rapacz M (1998) Physiological effects of winter rape (Brassica napus var. oleifera) prehardening to frost, II. Growth, energy partitioning and water status during cold acclimation. J Agron Crop Sci 181:81-87. doi:10.1111/j.1439-037X.1998.tb00402.x

Rapacz M (2007) Chlorophyll a fluorescence transient during freezing and recovery in winter wheat. Photosynthetica 45:409-418. doi: 10.1007/s11099-007-0069-2

Rapacz M, Gąsior D, Kościelniak J, Kosmala A, Zwierzykowski Z, Humphreys MW (2004) The role of the photosynthetic apparatus in cold acclimation of Lolium multiflorum. Characteristics of novel genotypes low-sensitive to PSII over-reduction. APP 29:309-316. doi:10.1007/s11738-007-0040-7

Rapacz M, Kościelniak J, Jurczyk B, Adamska A, Wójcik M (2010) Different patterns of physiological and molecular response to drought in seedlings of malt- and feed-type barleys (Hordeum vulgare). J Agron Crop Sci 196:9-19. doi:10.1111/j.1439-037X. 2009.00389.x

Roose JL, Yocum CF, Popelkova H (2011) Binding stoichiometry and affinity of the manganese-stabilizing protein affects redox reactions on the oxidizing side of photosystem II. Biochemistry 12(50(27)):5988-5998. doi:10.1021/bi2008068

Rudi H, Sandve SR, Opseth LM, Larsen A, Rognli OA (2011) Identification of candidate genes important for frost tolerance in Festuca pratensis Huds. by transcriptional profiling. Plant Sci 180:78-85. doi:10.1016/j.plantsci.2010.07.014

Sandve SR, Kosmala A, Rudi H, Fjellheim S, Rapacz M, Yamada T, Rognli OA (2011) Molecular mechanisms underlying frost tolerance in perennial grasses adapted to cold climates. Plant Sci 180:69-77. doi:10.1016/j.plantsci.2010.07.011

Sarvikas P, Hakala M, Pätsikkä E, Tyystjärvi T, Tyystjärvi E (2006) Action spectrum of photoinhibition in leaves of wild type and npq1-2 and npq4-1 mutants of Arabidopsis thaliana. Plant Cell Physiol 47:391-400. doi:10.1093/pcp/pcj006
Spetea C, Hundal T, Lundin B, Heddad M, Adamska I, Andersson B (2004) Multiple evidence for nucleotide metabolism in the chloroplast thylakoid lumen. Proc Natl Acad Sci USA 101:1409-1414. doi:10.1073/pnas.0308164100

Strasser RJ, Srivastava A, Govindjee (1995) Polyphasic chlorophyll a fluorescence transient in plants and cyanobacteria. Photochem Photobiol 61:32-42. doi:10.1111/j.1751-1097.1995.tb09240.x

Strasser RJ, Srivatava A, Tsimilli-Michael M (2000) The fluorescence transient as tool to characterize and screen photosynthetics samples. In: Yunus M, Pathre U, Mohanty P (eds) Probing photosynthesis: mechanism regulation and adaptation. Taylor and Francis, Bristol, pp 445-483

Takahashi S, Murata N (2008) How do environmental stresses accelerate photoinhibition? Trends Plant Sci 13:178-182. doi: 10.1016/j.tplants.2008.01.005

Thomas H, Humphreys MO (1991) Progress and potential of interspecific hybrids of Lolium and Festuca. J Agric Sci 117:1-8. doi: 10.1017/S0021859600078916

Yamamoto Y (2001) Quality control of photosystem II. Plant Cell Physiol 42:121-128. doi:10.1093/pcp/pce022

Yamamoto Y, Ishikawa Y, Nakatani E, Yamada M, Hang H, Wydrzynski T (1998) Role of an extrinsic 33 kilodalton protein of photosystem II in the turnover of the reaction center-binding protein D1 during photoinhibition. Biochemistry 37:1565-1574. doi:10.1021/bi9707640

Yamamoto Y, Aminaka R, Yoshioka M, Khatoon M, Komayama K, Takenaka D, Yamashita A, Nijo N, Inagawa K, Morita N, Sasaki T, Yamamoto Y (2008) Quality control of photosystem II: impact of light and heat stresses. Photosynth Res 98:589-608. doi:10.1007/s11120-008-9372-4 